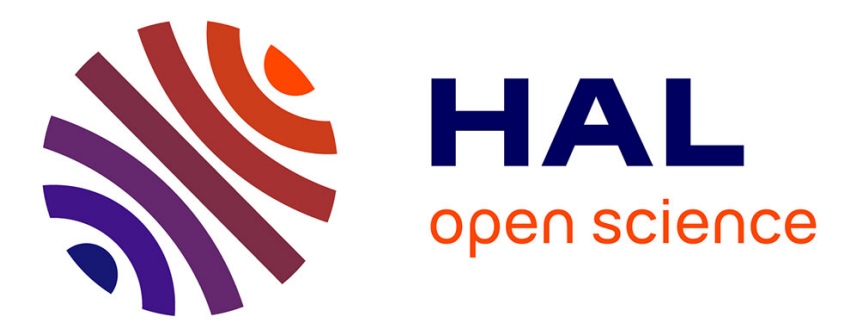

\title{
Reactions to Outgroup Authorities' Decisions: The Role of Expected Bias, Procedural Fairness and Outcome Favorability
}

\author{
Tomas Ståhl, Riël Vermunt, Naomi Ellemers
}

\section{> To cite this version:}

Tomas Ståhl, Riël Vermunt, Naomi Ellemers. Reactions to Outgroup Authorities' Decisions: The Role of Expected Bias, Procedural Fairness and Outcome Favorability. Group Processes and Intergroup Relations, 2008, 11 (3), pp.281-299. 10.1177/1368430208090643 . hal-00571688

\section{HAL Id: hal-00571688 \\ https://hal.science/hal-00571688}

Submitted on 1 Mar 2011

HAL is a multi-disciplinary open access archive for the deposit and dissemination of scientific research documents, whether they are published or not. The documents may come from teaching and research institutions in France or abroad, or from public or private research centers.
L'archive ouverte pluridisciplinaire HAL, est destinée au dépôt et à la diffusion de documents scientifiques de niveau recherche, publiés ou non, émanant des établissements d'enseignement et de recherche français ou étrangers, des laboratoires publics ou privés. 


\title{
Reactions to Outgroup Authorities' Decisions: The Role of Expected Bias, Procedural Fairness and Outcome Favorability
}

\author{
Tomas Ståhl and Riël Vermunt \\ Leiden University/University of Skövde
}

Naomi Ellemers

Leiden University

\begin{abstract}
It is argued here that expectations of bias (vs. no bias) play a key role in explaining reactions to decisions made by outgroup authorities. Two experiments demonstrate that decision acceptance (Experiment 1) and intentions to protest against an outgroup authority's decisions (Experiment 2) are affected by procedural fairness when the authority has a reputation of being unbiased, but not when the authority's reputation suggests bias. By contrast, some evidence is also found suggesting that reactions to an outgroup authority's decisions are affected by the favorability of the outcome when the authority has a reputation of being biased, but not when the authority has a reputation of being unbiased. Mediation analyses indicate that two different processes account for these effects.
\end{abstract}

KEYWORDS authority reputation, expected bias, intergroup perception, outcome favorability, procedural justice

IN THE globalized and multicultural world of today, societal and organizational authorities are frequently faced with the challenges of managing groups consisting of members of different subgroups. Research on procedural justice (for overviews, see Folger \& Cropanzano, 1998; Lind \& Tyler, 1988; Tyler \& Smith, 1998) has therefore started to examine how reactions to an authority's decisions are affected by the relationship people have to the authority. Several studies suggest that procedural fairness has a relatively modest influence on people's reactions to decisions when the decision-making authority is from an outgroup or from an ingroup that is of relatively minor relevance for their social identities (e.g. Huo, 2003; Huo, Smith, Tyler, \& Lind, 1996; Smith, Tyler, Huo, Ortiz, \& Lind, 1998;

\footnotetext{
$\overline{\text { Author's note }}$

Address correspondence to Tomas Ståhl, Leiden University, Section for Social and Organizational Psychology, P.O. Box 9555, 2300 RB Leiden, The Netherlands [email: tstahl@fsw.leidenuniv.nl]
} 
Ståhl, Van Prooijen, \& Vermunt, 2004; Tyler \& Degoey, 1995). In such situations, people's responses instead seem to be strongly affected by the favorability of decisions and decision-making procedures (Duck \& Fielding, 2003; Huo et al., 1996; Ståhl, Vermunt, \& Ellemers, 2006).

The primary aim of the present research is to examine psychological processes that may account for how people react to outgroup authorities' decisions. More specifically, we set out to explain the weak influence of procedural fairness and the strong influence of outcome favorability frequently found on reactions to outgroup authorities' decisions. In doing so, we also examine possibilities to enhance effects of procedural fairness and to reduce effects of outcome favorability. Our theoretical approach is primarily based on research on intergroup perception (e.g. Duck \& Fielding, 1999; Horwitz \& Rabbie, 1989; Kramer, Shah, \& Woerner, 1995; Moy \& Ng, 1996). Based on this literature we will argue that expectations about outgroup members play an important role in explaining reactions to outgroup authorities' decisions (cf. Duck \& Fielding, 1999, 2003; Ståhl et al., 2006). We will further argue that, by altering expectations about the outgroup authority, it is possible to direct people's concerns toward the fairness of treatment and away from the favorability of their outcome. Finally, we will also explore the mediating processes accounting for these changes. Before we go into the details of the present research, however, we shall start off by reviewing relevant research on reactions to outgroup members' decisions as well as work on intergroup perception.

\section{Reactions to outgroup members' decisions}

There are several studies indicating that the influence of procedural fairness on people's reactions to decisions made by an authority is relatively weak when the authority belongs to a group that is less important for their social identities. One relevant line of research has been carried out by Tyler and Huo and their colleagues (e.g. Huo, 2003; Huo et al., 1996; Tyler \& Degoey, 1995). The typical finding from these correlational studies is that associations between procedural fairness and subsequent reactions to decisions (e.g. decision acceptance) are weaker among people who do not identify with the group the authority represents. On the other hand, the same studies indicate that associations between outcome favorability and reactions to decisions become stronger the less people identify with the group.

Several studies have focused on the group membership of the authority rather than on people's level of identification with the group. Ståhl et al. (2004) found that while the fairness of procedures affected reactions to decisions when the authority was from an ingroup, this was generally not the case when the authority was from an outgroup. Smith et al. (1998) reported similar effects on people's self-esteem. By contrast, studies suggest that the favorability of outcomes (Duck \& Fielding, 2003) and procedures (Ståhl et al., 2004) exerts particularly strong influence on responses when the authority is from an outgroup.

But why do people react in this manner when faced with outgroup authorities? According to the relational model (Tyler \& Lind, 1992; cf. Lind \& Tyler, 1988), procedural fairness concerns are primarily relational in nature. People value a fair procedure because it indicates that they are respected and valued by the authority and by the group the authority represents. A consequence of this line of reasoning is that people should care less about procedural fairness as the relationship to the authority and the group becomes less relevant for their social identities (Huo et al., 1996). In the present article we argue that, aside from having weaker relational concerns, there is another reason why people react to decisions the way they do in encounters with outgroup authorities-people generally expect them to be biased.

\section{The role of expectations}

The literature on intergroup perception suggests that people generally perceive outgroup members as less trustworthy, less cooperative and less honest compared to ingroup members (e.g. Brewer, 1979). Furthermore, these negative 
biases also generalize to behavioral expectations. Several studies have found that people generally expect outgroup members to demonstrate bias in favor of their own group members in evaluation (Vivian \& Berkowitz, 1992) as well as in overt behavior (e.g. Duck \& Fielding, 1999; Harinck \& Ellemers, 2006; Horwitz \& Rabbie, 1989; Kramer et al., 1995; Moy \& Ng, 1996).

Given that outgroup members are generally expected to be biased, a relevant question is how such expectations affect reactions to decisionmaking procedures. ${ }^{1}$ To date, no studies have examined the role of expected bias in reactions to outgroup authorities' decisions. However, in ingroup settings and when the group is less salient, the literature suggests that procedural fairness effects, such as effects of voice (Folger, 1977), and accuracy (Leventhal, 1980) might be moderated by expected bias. For example, research on the voice effect indicates that one of the few conditions when positive effects of voice are not found is when people do not trust that the authority considers their views (Tyler, Rasinski, \& Spodick, 1985). De Cremer (2004) presented more direct experimental evidence that expected bias can moderate the influence of procedures. Specifically, when an authority who was expected to be biased evaluated participants' performance on various tests, procedural fairness judgments as well as emotional responses were equally negative regardless of whether the authority used accurate procedures or not. However, accuracy had a positive impact on procedural fairness judgments and emotional responses when the authority was expected to be unbiased. A plausible explanation to the findings of Tyler et al. (1985) and De Cremer (2004) is that people attach little value to procedural fairness rules such as voice and accuracy when they assume that these procedures are used strategically, rather than based on genuine intentions to be unbiased and fair (De Cremer, 2004; but see Van Prooijen, Van den Bos, Lind, \& Wilke, 2006).

How do these findings relate to encounters with outgroup authorities? We propose that because outgroup members are generally expected to be biased, in the absence of concrete information to the contrary, people do not expect outgroup authorities to have genuine intentions to be fair. As a result, procedural fairness effects (e.g. effects of voice) should be relatively weak in encounters with outgroup authorities (Ståhl et al., 2004). However, this line of reasoning would also imply that when an outgroup authority is expected not to be biased, people should be more inclined to react positively to fair procedures, as an absence of bias suggests that the authority has genuine intentions to be fair. For example, people should react positively to voice when the outgroup authority is expected to be unbiased, because they feel assured that their views will be considered. Based on this line of reasoning we hypothesize that the effect of voice on reactions to decisions made by an outgroup authority should be enhanced when the authority has a reputation of being unbiased rather than biased (Hypothesis 1).

Aside from affecting the value of procedural fairness, we argue that expected bias should also influence to what extent reactions to outgroup authorities' decisions are based on outcome favorability. Duck and Fielding (1999, 2003) suggested that because outgroup authorities are expected to be biased, people are particularly concerned about outcomes in such encounters to find out whether or not the bias they expect will actually emerge. We propose here that expected bias not only affects the extent to which people attend to outcomes, but also how people interpret and respond to the outcomes received. Research on evaluations of adversary trial procedures has shown that particularly negative responses to unfavorable outcomes are found when information suggests that the judge has a personal relationship to the party favored by the decision (Lind \& Lissak, 1985). Supposedly, this occurs because people suspect that the judge's personal relationship may influence the decision. Subsequently, when the outcome turns out to favor the person with whom the authority had a personal relationship, people easily conclude that their prior expectations have been confirmed. We argue here that, because outgroup members are generally expected to be biased in favor of members of their own group, reactions to decisions made by outgroup authorities are frequently the result of similar attributional 
processes. Specifically, whenever a decision favors one of the authority's ingroup members over an outgroup member, it is easy to attribute this to their common group membership. As a consequence, an unfavorable outcome that is seen to stem from bias may be perceived as unfair, and as a case of discrimination.

In short, we propose that reactions to decisions are strongly influenced by outcome favorability in encounters with outgroup authorities in part because outgroup members are expected to be biased. At the same time, this interpretation also implies that, when an outgroup authority is expected to be unbiased, the relative favorability of an outcome should have less influence on reactions to the outgroup authority's decisions. After all, when bias is not expected, it should be less likely that the outcome is attributed to one's group membership.

To the best of our knowledge, no studies to date have directly investigated this possibility. However, previous research indicates that expectations of bias affect allocation behavior toward the outgroup. Duck and Fielding (1999) found that the extent to which people expected an outgroup leader to be biased affected their own behavior toward the outgroup. Specifically, the more people expected the outgroup leader to be biased, the more they favored their own ingroup when allocating points in allocation matrices (see also Diehl, 1989, 1990; Ng, 1981). Duck and Fielding explained this finding by arguing that people compensated for anticipated ingroup disadvantage (cf. Moy \& Ng, 1996).

Indirect support for our line of reasoning can be derived from a recent study where people's reactions to outgroup authorities' decisions were examined as a function of their level of ingroup identification (Ståhl et al., 2006) . Because high ingroup identifiers differentiate between the ingroup and outgroup to a larger extent than do low identifiers (Doosje, Ellemers, \& Spears, 1995), it was argued that expectations of outgroup members as untrustworthy and biased should be particularly strong among high identifiers. As a consequence, it was expected (and found) that reactions to unfavorable treatment from an outgroup authority are particularly negative among high ingroup identifiers.
Importantly, however, expectations of bias were assumed rather than directly examined in this study. As a result, it is yet unknown whether expectations of bias enhance the influence of outcome favorability on reactions to outgroup authorities' decisions. In the present research we aim to examine this directly by experimentally manipulating whether an outgroup authority has a reputation of being biased or unbiased. Based on our line of reasoning and initial research, we predict that the effect of outcome favorability on reactions to decisions made by an outgroup authority is enhanced when the authority has a reputation of being biased rather than unbiased (Hypothesis 2).

We tested these hypotheses in two studies. In the first study we aimed to obtain preliminary support for the hypotheses by asking people how they would react to an outgroup authority who tends to be biased (vs. unbiased) and who used fair (vs. unfair) procedures to provide a favorable (vs. unfavorable) outcome. The second study was intended to replicate and extend the findings in a more self-involving setting where we also examined the mediating processes. In the first study we focused on people's evaluations of the outgroup authority following an allocation decision (e.g. Ståhl et al., 2004), and their willingness to accept the authority's decision (e.g. Huo et al., 1996) under different conditions. In the second study we focused on actual intentions to protest against the authority's decision (e.g. Ståhl, Vermunt, \& Ellemers, 2008; Vermunt, Wit, Van den Bos, \& Lind, 1996).

\section{Experiment 1}

\section{Method}

Participants and design Altogether, 128 students at the University of Skövde (97 females, 31 males, mean age $=25.69$ years $)$ were randomly assigned to conditions in a 2 (authority reputation: bias/no bias) $\times 2$ (procedure: voice/ no voice) $\times 2$ (outcome: favorable/unfavorable) factorial design.

Procedure The materials were distributed to participants during regular classroom sessions. Participants read the scenario and responded 
to the questions constituting the dependent variables and manipulation checks. Participants were asked to imagine the following scenario:

You are working in an organization. The organization consists of two departments, the Blue department and the Red department. You are a member of the Blue department. One day Robin Eriksson, a senior manager of the Red department, announces that the company has signed a contract with a new important client. This contract will yield an approximately equal amount of work for both the Blue department and the Red department. Now, the senior manager of the Red department announces, a person to take responsibility of the whole project needs to be appointed from either the Blue or the Red department. Getting this position would be a great career opportunity, and you would very much like to get the position. Robin Eriksson further suggests that you or Kim Svensson, an employee from the Red department, should get this position. Which one of you will get the position will be decided later on by Robin Eriksson.

After that, authority reputation was manipulated. Participants in the bias and no-bias conditions read (manipulated information in italics):

From other employees at the Blue department, you've received information that Robin Eriksson often/ never favors members of the Red department over members of the Blue department.

This was followed by the manipulation of procedure. Participants in the voice and novoice conditions read (manipulated information in italics):

Before the final decision is made, you and Kim Svensson are/are not given an opportunity to argue why you should get the position.

After that, the manipulation of outcome favorability took place. Participants in the favorable and unfavorable conditions read (manipulated information in italics):

Two weeks later Robin Eriksson, the assistant manager from the Red department, announces that you/Kim Svensson will get the position.

After that, all participants filled out the questions constituting the dependent variables and manipulation checks. Main dependent variables were participants' evaluations of the authority and their willingness to accept the authority's decision. We measured how the authority was evaluated by asking: 'Do you respect the decision maker?' $(1=$ absolutely not, $7=$ absolutely $)$ and 'Do you trust the decision maker?' $(1=$ absolutely not, $7=$ absolutely). Responses to these items were averaged to create a reliable measure of authority evaluations $(r=.84, p<.001)$. To measure decision acceptance we asked: 'To what extent are you willing to adhere to the decision?' $(1=$ not at all, $7=$ completely). To check the manipulation of bias we asked: 'According to other employees at your department, does the senior manager from the Red department favor employees at his own department?' $(1=$ yes, often, $2=$ no, never $)$. In order to check the manipulation of procedure two questions were asked: 'To what extent do you agree with the statement that you and Kim Svensson got an opportunity to argue for your cause before the decision was made?' $(1=n o t$ at all, $7=$ completely), and 'To what extent do you agree with the statement that you and Kim Svensson had no chance to argue for your cause before the decision was made?' $(1=$ not at all, $7=$ completely $)$. The second item was reversed after which the responses to the two items $(r=.82$, $p<.001)$ were averaged to create a procedure check. Finally, to check the manipulation of outcome favorability, two questions were asked: 'To what extent do you agree with the statement that you got the responsibility for the new client?' ( $1=$ not at all, $7=$ completely $)$, and 'To what extent do you agree with the statement that Kim Svensson got the responsibility for the new client?' ( $1=$ not at all, $7=$ completely $)$. The second item was reversed, after which the responses to the two items $(r=.97, p<.001)$ were averaged to create an outcome check.

\section{Results}

Manipulation checks A vast majority (117 out of $\left.128 ; \chi^{2}(1)=87.78, p<.001\right)$ of participants correctly responded to the authority reputation manipulation check. Because excluding the 11 participants who failed to correctly respond to this question yielded essentially the same results on the dependent variables, we decided to include them in the analyses. 
For all subsequent analyses we performed a 2 (authority reputation: bias/no bias) $\times 2$ (procedure: voice/no voice) $\times 2$ (outcome: favorable/unfavorable) analysis of variance (ANOVA). Participants in the voice condition agreed more with the statement that they had received an opportunity to argue for their cause $(M=5.94, S D=1.45)$, than participants in the no-voice condition $(M=1.55, S D=1.15)$ $\left(F(1,120)=352.81, p<.001\right.$, partial $\left.\eta^{2}=.75\right)$. Furthermore, participants in the favorable condition agreed more with the statement that they had received the new position $(M=6.59, S D=1.18)$, than participants in the unfavorable condition $(M=1.15, S D=0.59)$ $\left(F(1,120)=1044.56, p<.001\right.$, partial $\left.\eta^{2}=.90\right)$. No other effects were found. Thus, we conclude that all manipulations had been perceived as intended.

Authority evaluations Participants evaluated the authority more positively following a favorable outcome $(M=5.05, S D=1.68)$, than following an unfavorable outcome $(M=3.74, S D=1.75)$ $\left(F(1,120)=19.99, p<.001\right.$, partial $\left.\eta^{2}=.14\right)$. In addition, the authority was evaluated more positively following a voice procedure $(M=4.89$, $S D=1.69)$, than following a no-voice procedure $(M=3.93, S D=1.85)(F(1,120)=11.05, p<.005$, partial $\left.\eta^{2}=.08\right)$. More importantly, the predicted authority reputation by outcome interaction also was found $(F(1,120)=3.71, p<.06$, partial $\left.\eta^{2}=.03\right)$. As expected, participants in the bias condition evaluated the authority more positively following a favorable outcome $(M=5.13$, $S D=1.61)$ than following an unfavorable outcome $(M=3.27, S D=1.68)(F(1,120)=20.49, p<.001$, partial $\left.\eta^{2}=.15\right)$. The outcome effect was only marginally significant in the no-bias condition (Favorable, $M=4.97, S D=1.76$; Unfavorable, $M=4.23, S D=1.71)(F(1,120)=3.39, p<.07$, partial $\left.\eta^{2}=.03\right)$. Thus, support was found for Hypothesis 2. No other effects were significant, including the authority reputation by procedure interaction relevant for Hypothesis 1 . Instead, as indicated by the significant main effect, voice positively affected evaluations of the authority regardless of whether the authority had a reputation of being biased or not. We will return to this in the discussion.

Decision acceptance Participants were more willing to accept a favorable outcome $(M=6.46$, $S D=1.03)$, than an unfavorable outcome $(M=6.02 ; S D=1.34)(F(1,120)=4.47, p<.05$, partial $\left.\eta^{2}=.04\right)$. Overall, the procedure did not influence participants' actual acceptance of the decision $(F(1,120)=.33, p=.57$, partial $\left.\eta^{2}=.003\right)$. However, in line with Hypothesis 1 , the authority reputation by procedure interaction was significant $(F(1,120)=7.12, p<.01$, partial $\left.\eta^{2}=.06\right)$. As predicted, participants in the nobias condition were more willing to accept the decision following a voice procedure $(M=6.61$, $S D=0.67)$ than following a no-voice procedure $(M=5.94, S D=1.52)(F(1,120)=5.16, p<.05$, partial $\left.\eta^{2}=.04\right)$. By contrast, there was no significant effect of voice in the bias condition (Voice, $M=6.0, S D=1.44$; No voice, $M=6.44$, $S D=0.88)(F(1,120)=2.19, p=.14$, partial $\left.\eta^{2}=.02\right)$.

Notably, although the authority reputation by outcome interaction was not significant $\left(F(1,120)=.33, p=.57\right.$, partial $\left.\eta^{2}=.003\right)$, simple effect analyses indicated that the main effect of outcome found on decision acceptance was primarily attributable to reactions in the bias condition $(F(1,120)=3.62, p<.06$, partial $\left.\eta^{2}=.03\right)$, rather than in the no-bias condition $\left(F(1,120)=1.24, p=.27\right.$, partial $\left.\eta^{2}=.01\right)$. Thus, some support was obtained also for Hypothesis 2. We will return to this issue in the discussion.

\section{Discussion}

We have argued here that procedural fairness effects are relatively weak in encounters with outgroup authorities in part because outgroup members are generally expected to be biased. As a result, it was proposed that it should be possible to enhance procedural fairness effects by providing information suggesting that the outgroup authority is not biased. This prediction received initial support from this study which demonstrated that acceptance of the authority's decision was positively affected by voice when the authority had a reputation of being unbiased, but 
not when reputation suggested bias. However, this prediction was not supported by people's evaluations of the authority, as voice positively affected authority evaluations irrespective of the authority's reputation.

We also proposed that reactions to outgroup authorities' decisions are often based on the favorability of the outcome because outgroup authorities are expected to be biased. As a consequence, it was proposed that it should be possible to attenuate outcome favorability effects by providing information suggesting that the authority is unbiased. The results of this study offer some initial support for this argument as well. As expected, when the authority had a reputation of being biased, the favorability of the outcome had a stronger effect on people's evaluations of the authority than when the authority had a reputation of being unbiased. For actual acceptance of the authority's decision, however, only the main effect of outcome favorability reached statistical significance. As expected, the influence of outcome favorability on decision acceptance was somewhat stronger when the authority had a reputation of being biased (vs. unbiased). However, the moderating role of authority reputation was not strong enough to yield an interaction. In sum, support for our first hypothesis was found on decision acceptance, whereas some support for our second hypothesis was found primarily on evaluations of the authority.

Although not anticipated, the different patterns observed for authority evaluations and decision acceptance seem fairly reasonable in retrospect. Procedural fairness effects are generally particularly strong on evaluations of authorities, groups and institutions rather than on reactions to specific decisions (Tyler \& Lind, 1992). According to the relational model, this is because procedures convey information about the values of the group and its representatives (e.g. authorities). This implies that it should be relatively difficult to reduce effects of procedural fairness on evaluations of an authority. By contrast, previous research has demonstrated that decision acceptance is more closely linked to outcome favorability than other measures of legitimacy (Ståhl et al., 2004; Tyler, 1997). This implies that it should be particularly difficult to reduce the influence of outcome favorability on measures of decision acceptance.

Viewed in this light, the results reported here seem relatively straightforward. Irrespective of the authority's reputation, procedural fairness effects were obtained on the measure most closely connected to procedural fairness (authority evaluations). Thus, authority reputation did not have enough impact to moderate the robust link between procedural fairness and authority evaluations. In line with our first hypothesis, however, authority reputation did moderate the effect of procedural fairness on decision acceptance, a measure less closely connected to procedural fairness. By contrast, outcome favorability effects were obtained on the measure most closely linked to outcome favorability (decision acceptance) irrespective of the authority's reputation. In other words, our manipulation of authority reputation did not have enough impact to moderate the strong link between outcome favorability and decision acceptance. However, in line with our second hypothesis, authority reputation did moderate the influence of outcome favorability on evaluations of the authority, a measure less closely connected to outcome favorability.

The findings of this study are important, as they provide novel insights into the psychology of reactions to outgroup authorities' decisions, and ultimately about how reactions to such encounters can be altered. However, before strong conclusions can be drawn based on these findings it is important to replicate them. This is particularly important here as some of the results required post hoc interpretation. Another reason why an additional study seems critical is that the data in the first study were obtained by assessing participants anticipated responses. One may therefore wonder whether similar results can be found when people are actually subjected to the authority whose decision they are asked to respond to. Notably, previous research suggests that people tend to overestimate the influence of outcome favorability when asked how they would react to a decision as compared to how they actually do react to decisions (Tyler, Huo, \& Lind, 1999). It is therefore possible that the 
effects of outcome favorability obtained here were somewhat inflated. If this is the case, this could also help explain why authority reputation only slightly moderated the effect of outcome favorability on actual acceptance of the authority's decision in the present study. In the second study we address these issues as we examine the effects of authority reputation, procedural fairness and outcome favorability on responses to an outgroup authority's decisions in a more self-involving and consequential setting. As participants actually experience the manipulations in this study, we also decided to use a measure of their willingness to accept the decision that is more closely related to actual behavior-individual intentions to protest (Ståhl et al., 2008; Vermunt et al., 1996).

\section{Experiment 2}

Aside from providing a conceptual replication examining the responses of people who are actually immersed in the decision situation, we had an additional aim with our second study. In order to more fully understand the psychological processes at work, we wanted to investigate potential mediators for each of the two predicted effects.

In the first study we established that expected bias can moderate the effect of voice on responses to an outgroup authority's decisions. One of the aims of the second study was therefore to examine a potential mediator of this effect. At the core of our line of reasoning is the idea that expectations of bias affect the perceived value of procedural fairness rules (cf. De Cremer, 2004). When the authority is expected to be biased, the application of fair procedures should be perceived as relatively superficial and strategic, rather than based on sincere intentions to be fair. As a result, people should not be particularly satisfied with the way they are treated, even though procedures are formally in line with procedural fairness rules. For example, when voice is provided by a presumably biased authority, people should not be confident that the authority will actually consider their views. As a result, voice should have relatively little impact on how satisfied people are with the way they are treated by the authority. In situations where people do not expect bias, however, they should be more willing to rely on the authority's intentions, and to appreciate the value of an opportunity to voice their opinion.

In short, we expect that an outgroup authority's reputation (bias vs. no bias) and the fairness of the procedures used (e.g. voice vs. no voice) should interactively shape people's satisfaction with the treatment they receive. Furthermore, when controlling for differences in treatment satisfaction, we expect that authority reputation no longer should moderate the effect of procedural fairness on behavioral intentions following an outgroup authority's decision. In other words, when the authority has a reputation of being unbiased (vs. biased), people should be satisfied with their treatment when provided with an opportunity to voice their opinion, and therefore be more reluctant to protest. Thus, the extent to which people are satisfied with the treatment received should mediate the interaction between authority reputation and procedural fairness on protest intentions.

We also wanted to examine a potential mediator of the predicted interaction between authority reputation and outcome favorability on behavioral intentions following an outgroup authority's decision. We have argued here that, because outgroup members are generally expected to be biased, people easily attribute unfavorable decisions made by an outgroup authority to their group membership and hence may perceive unfavorable outcomes as examples of discrimination. This line of reasoning implies that outcome favorability should generally influence perceived outcome fairness in encounters with outgroup authorities. Indeed, previous research has demonstrated that outcome favorability does shape outcome fairness judgments in encounters with an outgroup authority (Duck \& Fielding, 2003). However, if our line of reasoning is accurate, outcome favorability should affect perceived outcome fairness particularly when the outgroup authority has a reputation of being biased rather than unbiased. Furthermore, when controlling for differences in perceived outcome fairness, we would expect that authority reputation no longer 
should moderate the influence of outcome favorability on intentions to protest against the outgroup authority's decision. In other words, when the authority has a reputation of being biased (vs. unbiased), people should perceive unfavorable outcomes as unfair, resulting in stronger intentions to protest. Thus, we predict that perceived outcome fairness should mediate the interaction between authority reputation and outcome favorability on intentions to protest.

To test these arguments we carried out an additional study in which we once again manipulated the outgroup authority's reputation (bias vs. no bias), procedure (voice vs. no voice) and the outcome (favorable vs. unfavorable). Main dependent variables were participants' intentions to protest against the decision, as well as the proposed mediators: treatment satisfaction and outcome fairness judgments.

\section{Method}

Participants and design Altogether, 128 students at the University of Skövde (97 females, 31 males, ${ }^{2}$ mean age $=24.31$ years ) participated before or after participating in another unrelated study. Participants were randomly assigned to conditions in a 2 (authority reputation: bias/ no bias) $\times 2$ (procedure: voice $/$ no voice $) \times 2$ (outcome: favorable/unfavorable) factorial design. All participants received a movie-ticket for their time in the laboratory.

Procedure Upon arrival at the laboratory all participants were led to separate cubicles. In each cubicle participants found a computer with a computer screen, a keyboard and a computer mouse. The computers were used to present the stimulus information as well as to collect the data. The experiment was introduced as a study on how individual cognitive strategies affect task performance. Participants then took part in the experiment and answered the questions constituting the dependent variables and manipulation checks.

In the first part of the instructions participants were informed that because the study focused on effects of individual cognitive strategies, the first aim was to measure these individual characteristics. After that, participants filled out a bogus Mental Association Style Test (e.g. Van Leeuwen, 2001). Then, participants received bogus feedback about their association style. Specifically, participants were informed that they had a holistic association style (as opposed to a detail-focused association style). Participants were then informed that the rest of the study focused on performance on specific tasks. Furthermore, participants were informed that, for the rest of the study, they participated along with two other persons. It was further noted that one of them (the participant included) would be appointed to the position of supervisor, referred to as position $\mathrm{A}$. The two remaining participants, it was announced, would be appointed to the positions of workers, referred to as positions B and C. After that, positions were assigned. Participants were all appointed to position B. Participants were informed that the persons appointed to positions B (the participant) and $\mathrm{C}$ were given these positions because they had not had previous experience with similar studies, and because they differed in their association styles. It was once again pointed out that B (the participant) had a holistic association style, whereas $\mathrm{C}$ had a detail-focused association style. Finally, participants were informed that the person appointed to position A was given this position because of this person's previous experience with similar studies (cf. Van den Bos, Wilke, \& Lind, 1998).

After that participants were informed that they would work on a certain task, and that at the end of the experiment, a bonus prize would be given to one of the workers (i.e. B or C). Participants were informed that the person appointed to position A (i.e. the supervisor position) would decide who should get the bonus prize. The task was then explained to the participants. The task was the same used in the experimental paradigm developed by Van den Bos and his colleagues (e.g. Van den Bos, Lind, Vermunt \& Wilke, 1997). A figure consisting of 36 squares with different patterns appears on the screen. The participants' task is to count the number of squares within the figure that has a certain pattern. As soon as the correct number of squares has been indicated, a new figure as well as a new pattern to identify 
appears on the screen. Participants work on the task in a practice round for 2 minutes followed by a work round of 10 minutes. The number of tasks solved in the work-round is calculated and displayed on the screen throughout the work-round.

Then it was communicated that, because $\mathrm{A}$ would be the supervisor, it might be of interest to know a little bit about $\mathrm{A}$, and how $\mathrm{A}$ had been perceived by participants in previous studies. Participants were then informed that A had a detail-focused association style, i.e. similar to person C but different from B (the participant). After that, authority reputation was manipulated. Participants received bogus results from a survey allegedly filled out by people who had participated with A in a previous study. In the bias condition, participants were informed that A had been rated as biased by participants with a holistic association style (i.e. by participants who belonged to the supervisor's outgroup), and as unbiased by participants with a detailfocused association style (i.e. by participants from the supervisor's ingroup). Participants in the no-bias condition were informed that A had consistently been rated as unbiased by participants with a detail-focused association style as well as by participants with a holistic association style.

Following the work round, participants were reminded of how many tasks they had completed. After that, all participants were informed that $\mathrm{C}$ performed an equivalent number of tasks. Then the procedure manipulation took place. Participants in the voice condition received a message from A informing them that A was interested in the participant's opinion concerning who should get the bonus prize. Participants in the voice condition then got to indicate their opinion concerning who should get the bonus prize. Participants in the no-voice condition received a message from $\mathrm{A}$ informing them that A was not interested in the participant's opinion concerning who should get the bonus prize. Therefore, it was communicated, the participant would not get an opportunity to voice his/her opinion on this matter (cf. Van den Bos, 1999). After that the favorability of the outcome was manipulated. Participants in the favorable condition were informed that $\mathrm{B}$ would receive the bonus prize. Participants in the unfavorable condition were informed that $\mathrm{C}$ would receive the bonus prize.

All participants then answered the questions constituting the dependent variables and manipulation checks. All items were measured on 7 -point Likert scales $(1=$ not at all; $7=$ very $m u c h)$. The main dependent variable was participants' individual intentions to protest. In addition, we also measured treatment satisfaction and outcome fairness judgments. To measure intentions to protest two questions were asked: 'Suppose that you could criticize person A; to what extent would you then do so?' and 'Suppose that you could protest against person A; to what extent would you then do so?'. These items were averaged to create a reliable protest intentions scale $(r=.78, p<.001)$. To measure treatment satisfaction three questions were asked: 'How satisfied are you with the way you were treated?', 'How dissatisfied are you with the way you were treated?', and 'How unhappy are you with the way you were treated?'. The last two items were reversed after which the three items were averaged to create a reliable treatment satisfaction scale $(\alpha=.83)$. To measure outcome fairness judgments two questions were asked: 'How fair was person A's decision about who should get the bonus prize?' and 'How correct was person A's decision about who should get the bonus prize?'. These items were averaged to create a reliable outcome fairness judgment scale $(r=.69, p<.001) .^{3}$

To check the manipulation of authority reputation we asked: 'To what extent do you agree with the statement that person $\mathrm{A}$ has shown unbiased behavior in the past?'. Two questions were asked to check the manipulation of procedure: 'To what extent do you agree with the statement that you received an opportunity to voice your opinion about who should get the bonus prize?' and 'To what extent do you agree with the statement that you did not receive an opportunity to voice your opinion about who should get the bonus prize?'. After reversing the second item, these items were averaged to create a reliable procedure check $(r=.91, p<.001)$. Finally, two questions were asked to check the 
manipulation of outcome: 'To what extent do you agree with the statement that you will get the bonus prize?' and 'To what extent do you agree with the statement that person $\mathrm{C}$ will get the bonus prize?'. After reversing the second item, these items were averaged to create a reliable outcome check $(r=.85, p<.001)$.

\section{Results}

All measures were analyzed by means of 2 (authority reputation: bias/no bias) $\times 2$ (procedure: voice/no voice) $\times 2$ (outcome: favorable/ unfavorable) ANOVAs.

Manipulation checks Participants in the nobias condition reported a stronger agreement with the statement that the authority had demonstrated unbiased behavior in the past $(M=4.47, S D=1.98)$ than participants in the bias condition $(M=3.03, S D=1.81)$ $\left(F(1,120)=18.30, p<.001\right.$, partial $\left.\eta^{2}=.13\right)$. No other effects were found on this measure. Most notably, the effectiveness of the authority reputation manipulation did not depend on the favorability of the outcome, as demonstrated by the fact that the authority reputation by outcome interaction was nonexistent $(F(1,120)=.04$, $p=.85$, partial $\left.\eta^{2}=.00\right)$. Participants in the voice condition agreed to a larger extent that they had received voice $(M=5.63, S D=1.88)$, than participants in the no-voice condition $(M=1.78$, $S D=1.58)(F(1,120)=168.65, p<.001$, partial $\left.\eta^{2}=.58\right)$. Although we also found a main effect of authority reputation $(F(1,120)=6.00, p<.05$, partial $\left.\eta^{2}=.05\right)$, and a three-way interaction $\left(F(1,120)=7.36, p<.01\right.$, partial $\left.\eta^{2}=.06\right)$, post hoc tests (Tukey) indicated that the only significant differences were found between all the voice conditions on the one hand, and all the no-voice conditions on the other $(p<.05)$. Based on the robust main effect of procedure (partial $\eta^{2}=.58$ ) and the fact that post hoc tests revealed no significant differences between conditions other than the ones intended, we think it is reasonable to conclude that the procedure manipulation was perceived as intended. Finally, participants in the favorable condition agreed more with the statement that they would get the bonus $(M=6.05, S D=1.24)$, than participants in the unfavorable condition $(M=1.40, S D=0.94)$ $\left(F(1,120)=562.60, p<.001\right.$, partial $\left.\eta^{2}=.82\right)$. No other effects were found on this measure. Thus we conclude that the manipulations were perceived as intended.

Protest intentions A main effect of procedure was found $(F(1,120)=7.50, p<.01$, partial $\left.\eta^{2}=.06\right)$. More importantly, however, this effect was qualified by a significant authority reputation by procedure interaction $(F(1,120)=4.19$, $p<.05$, partial $\eta^{2}=.03$ ). As predicted, participants in the no-bias condition reported stronger protest intentions when they did not receive voice $(M=4.36, S D=1.73)$, than when they did receive voice $(M=2.95, S D=1.38)$ $\left(F(1,120)=11.45, p<.001\right.$, partial $\left.\eta^{2}=.09\right)$. This difference was not found in the bias condition (No voice, $M=3.83, S D=1.83$; Voice, $M=3.63$, $S D=1.73)(F(1,120)=.24, p=.63$, partial $\left.\eta^{2}=002\right)$. Thus, support was found for our first hypothesis. Relevant for our second hypothesis, a marginally significant authority reputation by outcome interaction also was found $(F(1,120)$ $=2.80, p<.10$, partial $\left.\eta^{2}=.02\right)$. As expected, participants in the bias condition reported stronger protest intentions when the outcome was unfavorable $(M=4.09, S D=1.77)$ than when the outcome was favorable $(M=3.36, S D=1.71)$ $\left(F(1,120)=3.12, p=.08\right.$, partial $\left.\eta^{2}=.03\right)$. This difference was not found in the no-bias condition (Unfavorable, $M=3.53, S D=1.78$; Favorable, $M=3.78, S D=1.64)(F(1,120)=.36, p=.55$, partial $\left.\eta^{2}=.003\right)$. Thus, some support was found also for our second hypothesis. No other effects were found.

Treatment satisfaction Participants were more satisfied with their treatment following a favorable outcome $(M=5.52, S D=1.42)$ than following an unfavorable outcome $(M=4.33$, $S D=1.39)(F(1,120)=25.26, p<.001$, partial $\left.\eta^{2}=.17\right)$. A main effect of procedure also was found $\left(F(1,120)=7.58, p<.01\right.$, partial $\left.\eta^{2}=.06\right)$. Importantly, however, the procedure effect was qualified by the predicted authority reputation by procedure interaction $(F(1,120)=4.40, p<.05$, partial $\left.\eta^{2}=.04\right)$. As expected, participants in the no-bias condition were more satisfied following 
a voice procedure $(M=5.59, S D=1.32)$ than following a no-voice procedure $(M=4.44$, $S D=1.42)(F(1,120)=11.77, p<.005$, partial $\left.\eta^{2}=.09\right)$. This difference was not found in the bias condition (Voice, $M=4.91, S D=1.69$; No voice, $M=4.75, S D=1.46)(F(1,120)=.21$, $p=.64$, partial $\left.\eta^{2}=.002\right)$. No other effects were found.

Outcome fairness judgments Only an authority reputation by outcome interaction was found on this measure $(F(1,120)=4.15, p<.05$, partial $\left.\eta^{2}=.03\right)$. As predicted, perceived outcome fairness was higher in the bias condition following a favorable outcome $(M=4.45, S D=1.54)$ than following an unfavorable outcome $(M=3.81$, $S D=1.09)(F(1,120)=3.11, p=.08$, partial $\left.\eta^{2}=.03\right)$. This difference was not observed in the no-bias condition (Favorable, $M=3.89$, $S D=1.46$; Unfavorable, $M=4.30, S D=1.65$ ) $\left(F(1,120)=1.25, p=.27\right.$, partial $\left.\eta^{2}=.01\right){ }^{4}$

Mediation analyses Two different mediating processes were expected. First, satisfaction with the treatment received was expected to mediate the authority reputation by procedure interaction found on participants' protest intentions. Second, perceived outcome fairness was expected to mediate the marginal authority reputation by outcome interaction found on participants' protest intentions. To test these predictions we performed a series of regression analyses (Baron \& Kenny, 1986).
The results of the regression analyses testing the first predicted mediation are depicted in Figure 1 . To test the first predicted mediation, we started by regressing the expected mediator (treatment satisfaction) on the three independent variables (contrast coded -1 and 1 ) as well as all the interaction terms (including the three-way interaction). Confirming previous ANOVAs, the authority reputation by procedure interaction term predicted treatment satisfaction $(\beta=.17$, $p<.05)$. In the second step we regressed the dependent variable (intentions to protest) on the independent variables and all interaction terms. Once again confirming ANOVAs, intentions to protest were predicted by the authority reputation by procedure interaction term $(\beta=-.18$, $p<.05)$. After that, protest intentions were again regressed on the independent variables and interaction terms, but this time treatment satisfaction was included in the equation. As expected, treatment satisfaction significantly predicted intentions to protest $(\beta=-.54$, $p<.001)$. Furthermore, when treatment satisfaction was included in the analysis, the authority reputation by procedure interaction term no longer predicted protest intentions $(\beta=-.09$, $p=.26)$. The mediating role of treatment satisfaction was further supported by a Sobel test, $Z=-1.98, p<.025$ (one-tailed).

We then performed an equivalent set of regression analyses to test the second predicted mediating process: that outcome fairness should mediate the interaction between authority

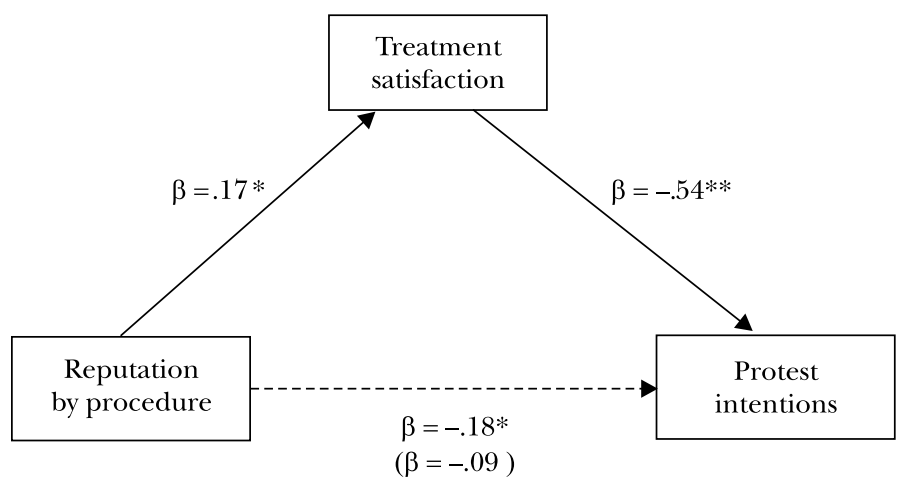

Figure 1. The indirect effect of the authority reputation by procedure interaction on protest intentions through treatment satisfaction. $* * p<.001 ; * p<.05$. 
reputation and outcome on protest intentions. The results of the regression analyses testing this mediation are depicted in Figure 2. Confirming previous ANOVAs, the authority reputation by outcome interaction term predicted outcome fairness $(\beta=-.18, p<.05)$. Regressing intentions to protest on all independent variables and interaction terms confirmed previous ANOVAs showing that the authority reputation by outcome interaction term served as a marginally significant predictor $(\beta=.14, p<.10)$. Finally, including outcome fairness in the equation confirmed that outcome fairness predicted intentions to protest $(\beta=-.33, p<.001)$. Furthermore, when outcome fairness was included in the analysis, the authority reputation by outcome interaction term no longer predicted protest intentions $(\beta=.08, p=.32)$. Our contention that outcome fairness acts as a (partial) mediator of the authority reputation by outcome interaction was further supported by a Sobel test, $Z=1.83$, $p<.05$ (one-tailed). ${ }^{5}$

\section{General discussion}

The research reported here was instigated to examine psychological processes contributing to reactions to allocation decisions made by members of an outgroup. Based on previous research on intergroup perception, we suggested that an important reason for the weak influence of procedural fairness on reactions to outgroup authorities' decisions is that people tend to perceive outgroup members as relatively untrustworthy, and expect them to be biased in favor of members of their own group. Based on this line of reasoning, we wanted to investigate whether it is possible to enhance the impact of procedural fairness on reactions to an outgroup authority's decisions by providing information that the authority is unbiased. This hypothesis was based on research indicating that the impact of procedural fairness (i.e. accuracy) is attenuated when the authority is expected to be biased (De Cremer, 2004), and studies suggesting that positive effects of voice disappear when people think that the authority will not truly consider their views (Tyler et al., 1985). Applying these results to encounters with outgroup authorities, we argued that pervasive expectations of outgroup members as biased might in part explain why procedural fairness typically seems less relevant as a determinant of people's reactions to outgroup authorities' decisions (e.g. Ståhl et al., 2004, 2006).

The results of both our studies supported this idea. In the first study, the fairness of the procedure (i.e. voice) had no effect on decision acceptance when the authority was expected to be biased, while voice had a substantial and positive effect on decision acceptance when the authority was expected to be unbiased. A similar pattern was obtained on participants' protest intentions in the second study. Specifically, protest intentions were unaffected by voice when the authority was expected to be biased, while

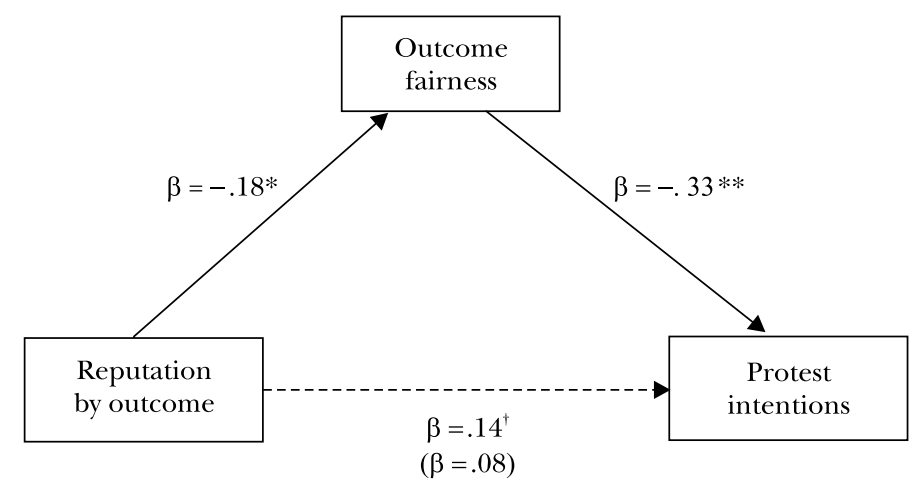

Figure 2. The indirect effect of the authority reputation by outcome interaction on protest intentions through outcome fairness. $* * p<.001 ; * p<.05 ;{ }^{\dagger} p<.10$. 
protest intentions were weaker following a voice (vs. no voice) procedure when the authority was expected to be unbiased. The present research is thereby the first to show that the way people respond to the procedural aspects of decisions made by an outgroup authority depends on the extent to which they expect this authority to be biased.

Additional mediation analyses of the second study support the contention that the effect is driven by the perceived value of procedural fairness. Specifically, our second study suggests that authority reputation and procedural fairness interactively shape how satisfied people are with the way they are treated, such that satisfaction is highest when an authority with a reputation of being unbiased uses a fair allocation procedure (i.e. voice). Our findings thus indicate that people can react to decisions made by outgroup authorities in ways similar to how they typically react in encounters with ingroup authorities, provided that the authority is expected to be unbiased. When this is the case, protest intentions are strongly influenced by procedural fairness.

A relevant question is exactly why the value of voice differs as a function of the authority's reputation. From an instrumental perspective it seems plausible that the authority's reputation affects perceptions of process control (Thibaut \& Walker, 1975). It might very well be that people think that they are unable to influence the decision by means of voice when the authority is biased against them. As a result, receiving or not receiving an opportunity to voice may be of little consequence. From a relational perspective, however, it would be argued that the authority's reputation moderates the level of respect communicated by a voice procedure. According to this view, an opportunity to voice does not indicate that one is respected by the authority if the authority is not thought to really consider what one has to say (Tyler et al., 1985). We suspect that both mechanisms may contribute to why an outgroup authority's reputation moderates the influence of voice, although this is of course an empirical question. For the time being, however, we conclude that an outgroup authority's reputation moderates the perceived value of voice and thereby the impact of voice on people's willingness to accept the authority's decisions.

An additional aim of the present research was to examine whether effects of outcome favorability are moderated by expected bias in encounters with an outgroup authority. In line with previous theorizing (Duck \& Fielding, 1999, 2003) we argued that when people expect the authority to be biased, they are particularly prone to pay attention and react to the favorability of the outcome to find out whether or not these expectations are confirmed. The two studies reported here provided some support for this line of reasoning by demonstrating that outcome favorability affects reactions to an outgroup authority's decision when the authority has a reputation of being biased. At the same time, our findings also extend previous research by showing that outcome favorability may be less important as a determinant of responses to decisions made by an outgroup authority when the authority has a reputation of being unbiased.

In the first study, outcome favorability affected participants' evaluations of the authority primarily when information indicated that the authority was biased. However, it should be noted that outcome favorability influenced actual acceptance of the authority's decision irrespective of the authority's reputation, although the influence was somewhat weaker when bias was not expected. We believe these inconsistencies are in part due to the fact that decision acceptance is more closely linked to instrumental concerns than other measures of legitimacy (Tyler, 1997). However, they are most likely attributable to the specific methodology used in the first study as well. Research has shown that when asked how they would react to decisions (as in the first study), people tend to overestimate the influence of outcome favorability, as compared to how they actually do react to decisions (Tyler et al., 1999). Indeed, in our second study, where people reacted to an actual experience of the same manipulations, the effects of outcome favorability were generally less pronounced. More importantly, authority reputation moderated the effect of outcome favorability on intentions to protest against the 
outgroup authority's decision. In line with our second hypothesis, participants' intentions to protest against the outgroup authority's decision were affected by the favorability of the outcome, but only when the authority had a reputation of being biased. When the authority had a reputation of being biased, intentions to protest against the decision were stronger following an unfavorable outcome than following a favorable outcome. By contrast, when the authority had a reputation of being unbiased, protest intentions were unaffected by the favorability of the outcome.

The second study provided additional insight into the psychological processes driving this effect. Previous research has shown that outcome favorability shapes fairness judgments in encounters with outgroup authorities (Duck \& Fielding, 2003), an effect that has been interpreted as a reaction to perceptions of bias. Building on this line of reasoning, we proposed and demonstrated that perceptions of outcome fairness mediate the interaction effect between authority reputation and outcome favorability on protest intentions following an outgroup authority's decision. An interesting implication of these findings is that reactions to outgroup authorities' decisions, that on the surface appear to be driven solely by self-interest, seem to be largely driven by fairness concerns. Specifically, our findings suggest that protest intentions following an outgroup authority's decision are guided by fairness concerns. However, unless information clearly indicates that the authority is unbiased, outgroup authorities will be expected to favor their own group members. As a result, when bias is expected, fairness judgments as well as protest intentions will be influenced by the favorability of the outcome. Expressed differently, our findings suggest that people respond to the favorability of outcomes in encounters with outgroup authorities that are expected to be biased, but that they do so in part out of concerns for fairness.

Although we think that the findings reported here provide relatively strong evidence for the role of expected bias, and are important as they are the first to directly point to the relevance of bias expectations in encounters with outgroup authorities, the studies also have some limitations that need to be addressed. First, although we observed the predicted mean pattern, the authority reputation by outcome interaction relevant for our second hypothesis was marginally significant in these two studies. This was obviously somewhat disappointing, and also warrants some caution in our conclusions. At the same time, however, we think the fact that the pattern was in line with our prediction across two studies in which different methodologies were used, suggests that the findings are reliable.

A second point to address is the fact that participants in these studies were given explicit information about the authority's reputation of being biased (vs. unbiased). This provided a clear manipulation of expected bias, which was suitable here, as our main objective was to demonstrate the causal role of expected bias in reactions to outgroup members' decisions. However, one might wonder about the boundary conditions for effects of expected bias. For example, would mere categorization of the authority as an outgroup member, with accompanying implicit expectations of bias (e.g. Duck \& Fielding, 1999), be enough to obtain similar effects? Now that the effects of expected bias on reactions to outgroup authorities' decisions have been demonstrated, we think this would be a fruitful direction for future research.

Because the present research exclusively examined the role of authority reputation in reactions to decisions made by an outgroup authority, one may wonder whether a reputation of bias would initiate similar processes in interactions with an ingroup authority. We suspect that there may be situations where processes rather similar to the ones observed in the present research do operate in a pure intragroup context. For example, a schoolteacher could have a reputation of favoring a particular student over other students in the class, as illustrated by the expression 'Teacher's pet'. Notably, this type of bias is based on personal characteristics rather than group membership. Nevertheless, we suspect that the consequences of such a reputation for how people evaluate decisions may be quite similar as when an outgroup authority has a reputation of bias based on 
group membership. Voice opportunities may be perceived as superficial and outcomes favoring a 'teacher's pet' may be perceived as unfair.

But how would people react to an ingroup authority with a reputation of group-based bias? In such cases we suspect that reactions would be rather different from the ones observed in the present research. The main reason for this is that an ingroup authority with a reputation of groupbased bias should raise very different concerns than a biased outgroup authority. Rather than expecting to be discriminated against, concerns would center around the possibility that oneself might be favored at the expense of outgroup members. What consequences could such concerns have for how people react to an ingroup authority's decisions? First, we would not expect people to discard the value of an opportunity to voice their opinion. After all, when an authority is supposedly biased in favor of oneself, an opportunity to voice should still indicate process control, as well as that one is respected by the authority, which should be particularly self-relevant in the case of an ingroup authority. As a result, and in contrast to what we found in the present research, we would expect people to react positively to an opportunity to voice from an ingroup authority even when the authority has a reputation of bias.

Second, concerns that one might be favored over outgroup members should not cause people to attribute unfavorable outcomes to discrimination. If anything, favorable outcomes should be attributed to (positive) discrimination. However, people might be reluctant to conclude that an ingroup authority has discriminated an outgroup member solely based on the favorability of an outcome, particularly if the reputation of bias stems from outgroup members. Aside from a favorable outcome for themselves, we suspect that people may require less ambiguous evidence that the procedure was unfair in order to conclude that group membership played a role in the decision process. Thus, in the case of an ingroup authority, it seems plausible that authority reputation, outcome favorability and procedural fairness may all interact to shape reactions to decisions. In short, we think the present results are specific to reactions to outgroup authorities, not authorities in general, and we would expect rather different psychological processes to operate and different reactions to emerge when an ingroup authority has a reputation of being biased.

Obviously, the ideas outlined above have yet to be tested empirically. The main reason we chose not to examine these issues in the present research was parsimony. Ultimately, our main objective in this line of research was to understand the consequences of expecting an outgroup authority to be biased against oneself based on one's group membership. As indicated by the experimental designs in the present research, explaining these processes was already quite complex. We were therefore reluctant to add further complexity that might enable us to additionally address the rather different question of what the consequences are of expecting an ingroup authority to be biased in favor of oneself based on one's group membership. Nevertheless, because we would expect rather different psychological processes to operate, we do think this is an interesting issue that might be further examined in future research.

To conclude, the findings of the present research are important as they provide novel information about the psychological processes involved in reactions to outgroup authorities' decisions. The main message to social justice scholars conveyed by the present research is that it is of utmost importance to consider people's expectations of outgroup members as biased in order to understand reactions to decisions made by outgroup authorities. Expectations of bias are important to consider in such situations because they can affect the influence of procedural fairness as well as outcome favorability. Finally, from a practical perspective, our findings suggest ways to alter reactions to outgroup authorities' decisions such that the influence of procedural fairness can be increased and effects of outcome favorability can be reduced. Such information is of great practical value, in particular as many societal resources are expected to become increasingly scarce. The main message to authorities allocating resources between members of different groups or subgroups is that there may be much to be gained 
in providing explicit and truthful information about absence of bias. Such demonstrations can pave the way for less outcome oriented reactions to the authority's decisions, and for a stronger influence of procedural fairness.

\section{Notes}

1. In the present article bias refers specifically to a tendency to favor certain individuals over others in allocation decisions. For example, an authority with a tendency to favor members of his/her ingroup over members of an outgroup would be considered as biased from this perspective.

2. The fact that the number of male and female participants is the same as in Study 1 is coincidental. The studies were not run at the same time, nor using the same participants.

3. Not surprisingly, there was a moderate negative correlation between protest intentions and treatment satisfaction $(r=-.52, p<.001)$, as well as between protest intentions and outcome fairness $(r=-.37, p<.001)$. Finally there was a moderate positive correlation between treatment satisfaction and outcome fairness $(r=.51, p<.001)$. To confirm our conceptual differentiation between these three dependent variables, we performed a Principal Components Analysis (with Varimax rotation) on all the items. This analysis supported our three-factor solution. The three factors accounted for a total of $82 \%$ of the variance, and all items showed high factor loadings on the relevant factor (factor loadings $>.76$ ), and low loadings on other factors (factor loadings $<.33$ ) .

4. We also checked whether our results were affected by participants' expressed opinions on how to allocate the bonus. Overall, participants in the voice condition preferred themselves rather than the other to receive the bonus. Furthermore, participants expressed more satisfaction with their treatment and perceived the outcome as more fair when the authority's decision was consistent with their own preferences. Importantly, however, participants' expressed opinions as well as their reactions to the consistency between their expressed opinion and the decision outcome were unaffected by the authority reputation manipulation. Thus, participants' expressed opinions and the consistency between their expressed opinions and the decision outcome do not contribute to our main results.

5. We also ruled out two alternative mediating processes. First of all we tested whether outcome fairness mediated the authority reputation by procedure interaction on intentions to protest. However, outcome fairness was not predicted by the authority reputation by procedure interaction $(\beta=.10, p=.26)$. Moreover, a Sobel test confirmed that the authority reputation by procedure effect on intentions to protest was not mediated by outcome fairness $(Z=-1.09, n s)$. Second, we also tested whether treatment satisfaction mediated the authority reputation by outcome interaction on intentions to protest. However, treatment satisfaction was not predicted by the authority reputation by outcome interaction $(\beta=-.05, p=.55)$. A Sobel test further confirmed that the authority reputation by outcome effect on intentions to protest was not mediated by treatment satisfaction $(Z=0.58, n s)$.

\section{Acknowledgments}

The research reported in this article was supported by the University of Skövde. We would like to thank Eric van Dijk for his valuable comments on an earlier version of this manuscript.

\section{References}

Baron, R. M., \& Kenny, D. A. (1986). The moderator-mediator variable distinction in social psychological research: Conceptual, strategic and statistical considerations. Journal of Personality and Social Psychology, 51, 1173-1182.

Brewer, M. B. (1979). In-group bias in the minimal intergroup situation: A cognitive-motivational analysis. Psychological Bulletin, 86, 307-324.

De Cremer, D. (2004). The influence of accuracy as a function of leader's bias: The role of trustworthiness in the psychology of procedural justice. Personality and Social Psychology Bulletin, 30, 293-304.

Diehl, M. (1989). Justice and discrimination between minimal groups: The limits of equity. British Journal of Social Psychology, 28, 227-238.

Diehl, M. (1990). The minimal group paradigm: Theoretical explanations and empirical findings. In W. Stroebe \& M. Hewstone (Eds.), European review of social psychology (Vol. 1, pp. 263-292). Chichester, UK: Wiley. 
Doosje, B., Ellemers, N., \& Spears, R. (1995). Perceived intragroup variability as a function of group status and identification. Journal of Experimental Social Psychology, 31, 410-436.

Duck, J. M., \& Fielding, K. S. (1999). Leaders and subgroups: One of us or one of them? Group Processes $\mathcal{E}$ Intergroup Relations, 2, 203-230.

Duck, J. M., \& Fielding, K. S. (2003). Leaders and their treatment of subgroups: Implications for evaluations of the leader and the superordinate group. European Journal of Social Psychology, 33, 387-401.

Folger, R. (1977). Distributive and procedural justice: Combined impact of 'voice' and improvement on experienced inequity. Journal of Personality and Social Psychology, 35, 108-119.

Folger, R., \& Cropanzano, R. (1998). Organizational justice and human resource management. Thousand Oaks, CA: Sage.

Harinck, F., \& Ellemers, N. (2006). Playing hide and seek: The effects of revealing one's personal interests in intra- and inter-group negotiations. European Journal of Social Psychology, 36, 791-813.

Horwitz, M., \& Rabbie, J. M. (1989). Stereotypes of groups, group members and individuals in categories: A differential analysis. In D. Bar-Tal (Ed.), Stereotyping and prejudice: Changing conceptions (pp. 105-129). New York: Springer-Verlag.

Huo, Y. J. (2003). Procedural justice and social regulation across group boundaries: Does subgroup identity undermine relationship-based governance? Personality and Social Psychology Bulletin, 29, 336-348.

Huo, Y. J., Smith, H. J., Tyler T. R., \& Lind, E. A. (1996). Superordinate identification, subgroup identification, and justice concerns: Is separatism the problem; is assimilation the answer? Psychological Science, 7, 40-45.

Kramer, R. M., Shah, P. P., \& Woerner, S. L. (1995). Why ultimatums fail: Social identity, and moralistic aggression in coercive bargaining. In R. M. Kramer \& D. M. Messick (Eds.), Negotiation as a social process (pp. 285-308). Thousand Oaks, CA: Sage.

Leventhal, G. S. (1980). What should be done with equity theory? New approaches to the study of fairness in social relationships. In K. J. Gergen, M. S. Greenberg, \& R. H. Willis (Eds.), Social exchange: Advances in theory and research (pp. 27-54). New York: Plenum.

Lind, E. A., \& Lissak, R. (1985). Apparent impropriety and procedural fairness judgments. Journal of Experimental Social Psychology, 21, 19-29.
Lind, E. A., \& Tyler, T. R. (1988). The social psychology of procedural justice. New York: Plenum.

Moy, J., \& Ng, S. H. (1996). Expectation of outgroup behavior: Can you trust the outgroup? European Journal of Social Psychology, 26, 333-340.

$\mathrm{Ng}, \mathrm{S}$. H. (1981). Equity theory and the allocation of rewards between groups. European Journal of Social Psychology, 11, 439-444.

Smith, H. J., Tyler, T. R., Huo, Y. J., Ortiz, D. J., \& Lind, E. A. (1998). The self-relevant implications of the group-value model: Group membership, self-worth, and treatment quality. Journal of Experimental Social Psychology, 34, 470-493.

Ståhl, T., Van Prooijen, J.-W., \& Vermunt, R. (2004). On the psychology of procedural justice: Reactions to procedures of ingroup vs. outgroup authorities. European Journal of Social Psychology, 34, 173-189.

Ståhl, T., Vermunt, R., \& Ellemers, N. (2006). Friend or foe? Ingroup identification moderates reactions to outgroup members' allocation behavior. European Journal of Social Psychology, 36, 877-885.

Ståhl, T., Vermunt, R., \& Ellemers, N. (2008). For love or money? How activation of relational versus instrumental concerns affects reactions to decision-making procedures. Journal of Experimental Social Psychology, 44, 80-94.

Thibaut, J., \& Walker, L. (1975). Precedural justice: A psychological analysis. Hillsdale, NJ: Erlbaum.

Tyler, T. R. (1997). The psychology of legitimacy: A relational perspective on voluntary deference to authorities. Personality and Social Psychology Review, 1, 323-345.

Tyler, T. R., \& Degoey, P. (1995). Collective restraint in social dilemmas: Procedural justice and social identification effects on support for authorities. Journal of Personality and Social Psychology, 69, 482-497.

Tyler, T. R., Huo, Y. J., \& Lind, E. A. (1999). The two psychologies of conflict resolution: Differing antecedents of pre-experience choices and post-experience evaluations. Group Processes $\mathcal{E}^{\circ}$ Intergroup Relations, 2, 99-118.

Tyler, T. R., \& Lind, E. A. (1992). A relational model of authority in groups. In M. Zanna (Ed.), Advances in experimental social psychology (Vol. 25, pp. 115-191). San Diego, CA: Academic Press.

Tyler, T. R., Rasinski, K. A., \& Spodick, N. (1985). Influence of voice on satisfaction with leaders: Exploring the meaning of process control. Journal of Personality and Social Psychology, 48, 72-81. 
Tyler, T. R., \& Smith, H. J. (1998). Social justice and social movements. In D. Gilbert, S. T. Fiske, \& G. Lindzey (Eds.), Handbook of social psychology (4th ed., Vol. 2, pp. 595-629). Boston: McGraw-Hill.

Van den Bos, K. (1999). What are we talking about when we talk about no-voice procedures? On the psychology of the fair outcome effect. Journal of Experimental Social Psychology, 35, 560-577.

Van den Bos, K., Lind, E. A., Vermunt, R., \& Wilke, H. A. M. (1997). How do I judge my outcome when I do not know the outcome of others? The psychology of the fair process effect. Journal of Personality and Social Psychology, 72, 1034-1046.

Van den Bos, K., Wilke, H. A. M., \& Lind, E. A. (1998). When do we need procedural fairness? The role of trust in authority. Journal of Personality and Social Psychology, 75, 1449-1458.

Van Leeuwen, E. (2001). Preserving identity when groups combine: A study of group-based reactions to mergers. Unpublished doctoral dissertation, Leiden University.

Van Prooijen, J.-W., Van den Bos, K., Lind, E. A., \& Wilke, H. A. M. (2006). How do people react to negative procedures? On the moderating role of authority's biased attitudes. Journal of Experimental Social Psychology, 5, 632-645.

Vermunt, R., Wit, A., Van den Bos, K., \& Lind, E. A. (1996). The effects of unfair procedure on negative affect and protest. Social Justice Research, 9, 109-119.

Vivian, J. E., \& Berkowitz, N. H. (1992). Anticipated bias from an outgroup: An attributional analysis. European Journal of Social Psychology, 22, 415-424.

Paper received 29 November 2006; revised version accepted 18 January 2008.

\section{Biographical notes}

TOMAS STÅHL (PhD University of Leiden, 2006) is a post doctorate researcher in social psychology at the University of Leiden. The research reported in this article was prepared at the University of Skövde as part of his PhD project. Dr Ståhl's research interests include the consequences of social stigma, the psychology of procedural justice, and victim-blaming phenomena.

RIËL VERMUNT (PhD University of Leiden, 1981) is a retired associate professor in social psychology (University of Leiden and University of Skövde). Dr Vermunt's experimental and applied research focuses on theory construction in social justice, stress, self esteem, asymmetry phenomena in social perception, and social comparison.

NAOMI ELLEMERS (PhD University of Groningen, 1991) is a professor of social and organizational psychology at the University of Leiden, and a full member of the Kurt Lewin Institute in the Netherlands. Dr Ellemers' research covers the broad area of group processes and intergroup relations, and includes basic experimental research as well as applied work in organizations. 